ORIGINAL ARTICLE

\title{
Assessing safety awareness and knowledge and behavioral change among West Virginia loggers
}

\author{
J C Helmkamp, J L Bell, W J Lundstrom, J Ramprasad, A Haque
}

Injury Prevention 2004;10:233-238. doi: 10.1136/ip.2003.005033

See end of article for authors' affiliations

.....................

Correspondence to: Dr James C Helmkamp, Center for Rural

Emergency Medicine, West Virginia University, PO Box 9151,

Morgantown

WV 26506-9151, USA;

jhelmkamp@hsc.wvu.edu
Objective: To determine if a video used during logger training influences safety attitude, knowledge, and workplace habits.

Method: From April 2002 to October 2003, loggers receiving training through the West Virginia Division of Forestry were given a new safety module. This consisted of a pre-training survey, viewing video, brief introduction to field safety guide, and an immediate post-training survey. Six months after training, loggers were contacted by telephone to assess workplace behavioral changes.

Results: 1197 loggers attended 80 training sessions and completed surveys; $21 \%$ were contacted at follow up. Pre-training surveys indicated that half said "accidents" were part of the job and had experienced a "close call" in their work. An overwhelming majority felt that safety management and periodic meetings were important. Over $75 \%$ indicated they would not take risks in order to make a profit. Several statistically significant improvements were noted in safety knowledge after viewing the video: logger's location in relation to the tree stump during fatal incidents and the pictorial identification of an overloaded truck and the safest cutting notch. At follow up, many of the loggers said they related to the real life victim stories portrayed in the video. Further, the field guide served as a quick and easy reference and taught them valuable tips on safe cutting and felling.

Conclusions: Significant changes in safety knowledge and attitude among certified loggers resulted from viewing the video during training. Subsequent use of the video and field guide at the worksite encouraged positive change in self reported work habits and practices.
W orkers in the logging industry are exposed to serious hazards and are at increased risk for non-fatal and fatal injuries. ${ }^{1-22}$ In 2002, the United States logging industry had a fatality rate (117.8 deaths per 100000 workers) substantially higher than the overall national occupational fatality rate of 4.0 and other industries such as coal mining (28.7) and construction (12.2)..$^{78}$

Injuries to West Virginia loggers are more likely to result in death compared with coal mining and construction. From 1998-2001, loggers (SIC 241, average annual workforce of 1472) died at a rate of 405 deaths per $100000 .^{15}$ This is significantly higher than rates for coal mining and construction, both with substantially larger annual workforces and lower rates-coal mining (SIC 122): 21975 and 44.4 deaths per 100000 and construction (SIC 16 and 17): 33800 and 20.0 deaths per $100000 . .^{914}{ }^{23}$ Mountainous terrain, predominance of hardwood species with large diameters and irregular shapes, and low levels of mechanized harvestingcharacteristics of logging in West Virginia-exacerbate this risk. ${ }^{1013} 15$

Loggers are also at a higher risk for non-fatal injuries. A study of West Virginia workers' compensation claims from 1996 to 2001 for non-fatal logging injuries reported an average annual rate of 16.0 claims per 100 loggers. ${ }^{15}$ During this same period, the Bureau of Labor Statistics reported a national rate of 8.5 total non-fatal injury cases per 100 loggers recordable by the Office of Safety and Health Administration (OSHA). ${ }^{24}$ Because virtually all of West Virginia workers' compensation claims would be considered recordable by the OSHA, the two rates are comparable, suggesting that the West Virginia rate is almost twice the national rate. ${ }^{15}$

Based on the recent logging industry fatality experience in West Virginia, the National Institute for Occupational Safety and Health-funded West Virginia Fatality Assessment and
Control Evaluation (WVFACE) Program ${ }^{15}$ embarked on a long term project, in collaboration with the West Virginia Division of Forestry (WVDOF), to develop a safety module to educate loggers on the common hazards of their industry with the overall goal to reduce the number of injuries. The safety module included three phases: (1) incorporation of a video into required logger training and using pre-training and immediate post-training surveys to determine its impact in improving knowledge and attitude about safety; (2) the distribution and use of a logger's field safety guide and video at the worksite to further emphasize worker safety; and (3) a telephone survey six months after training to see if worksite practices changed.

\section{METHODS}

Companies logging in West Virginia are required by state law to have at least one certified logger supervising each crew $^{25}$; this logger must be on the job each day but does not have to be continuously present. Certification involves a 2-3 day training session incorporating best management practices, logging operations/chainsaw safety, and verification of first aid/cardiopulmonary resuscitation training. Recertification, required within three years of initial certification, involves a one day session covering best management practices update, environmental practices, WVDOF district elective topics (for example, roads, maps, reclamation, etc), and verification of a valid first aid card. ${ }^{25} 26$ In addition, state OSHA usually presents information on the logging standard in both certification and recertification classes. This standard establishes

Abbreviations: OSHA, Office of Safety and Health Administration; WVDOF, West Virginia Division of Forestry; WVFACE, West Virginia Fatality Assessment and Control Evaluation; WVU, West Virginia University 
safety practices, methods, and operations for all types of logging. ${ }^{27}$

Since April 2002, a "safety module" was added to all certified logger training classes conducted throughout the six WVDOF state forest districts. The first phase of the 45 minute safety module consisted of: (1) explanation of project and written consent; (2) pre-training survey assessing safety knowledge and attitude; (3) viewing 13 minute video and very brief introduction to the logger's field guide; and (4) immediate post-training survey. After the first phase, videos and field guides were given to each logger to share with coworkers at the worksite. The final phase was a telephone survey six months after training to determine if loggers had shared the video and field guide and to see if these had influenced worksite habits. Information was not collected on logger's age, experience, or education during any of the phases.

The video, Some Mistakes Last Forever, produced by WVFACE and the West Virginia University (WVU) Center for Rural Emergency Medicine featured vignettes of loggers talking about their injury experiences. Each depicted experience represents at least one WVFACE identified causal factor (for example, logs rolling off overloaded trucks, unsafe escape paths, etc) and its corresponding prevention strategy.

The WV Logger's Safety Field Guide, a spiral bound and illustrated pocket reference, offers basic safety tips for a variety of logging tasks. Topics included implementing and managing a company safety program, felling, limbing and bucking, log loading, chain saw safety, and basic first aid.

Loggers who viewed the video during training may have worked for companies that participated in the West Virginia Loggers Safety Initiative Program. This program, begun in July 1999, is a partnership between the WVDOF, the West Virginia Forestry Association, the WVU Appalachian Hardwood Center, the West Virginia Workers' Compensation Commission, and logging companies throughout West Virginia. The objective of the Loggers Safety Initiative was to change the culture related to logging safety and its associated costs. ${ }^{28} 29$ The main components were training, accountability, and financial incentive (that is, companies completing Loggers Safety Initiative requirements receive a reduction in workers' compensation premium payments). Between July 1999 and June 2003 when the Loggers Safety Initiative ended, nearly 100 active West Virginia logging companies voluntarily participated in activities ranging from primary job training sessions (for workers other than fellers), safety, productivity, conservation and cutting techniques, and compliance inspections. ${ }^{28} 29$

To facilitate direct comparisons of logger responses before and after viewing the video, 13 knowledge based questions were repeated in the pre-training and immediate posttraining surveys. All of these were covered in the video, with nine repeated verbatim from audiotext and the other four from diagrams or pictures. Loggers could choose not to answer questions from any of the three surveys. If there was insufficient identification (that is, legible name) to link logger's surveys together, or if a logger did not sign the consent form, their data were not used. Information collected is presented as counts and proportions. The information on attitudes collected was also presented in terms of counts and proportions within a Likert framework (that is, agree, neutral, or disagree). The proportion of loggers responding incorrectly to questions after viewing the video divided by the proportion of loggers responding incorrectly before the video results in a ratio, when subtracted from 1.0, that indicates the amount of improvement (that is, \%) that could be attributed to the video. ${ }^{30}{ }^{31}$ Changes observed among all loggers and between subgroups (for example, certified $v$ recertified, owners $v$ non-owners, and Loggers Safety Initiative $v$
non-Loggers Safety Initiative) were assessed using a $\chi^{2}$ test. One would hypothesize that fewer respondents would answer questions incorrectly after viewing the video, thus showing improved knowledge and awareness as a result of the video.

\section{RESULTS}

From April 2002 through October 2003, a total of 1541 loggers attended 80 WVDOF training sessions. Full consent was obtained for $78 \%$ (1197). Reasons for elimination (from the database) included previously viewing the video (170), consent forms not signed or initialed (56), and surveys that could not be matched by name (118). Two thirds of those who consented attended the recertification sessions with the remaining third receiving their initial certification. About $60 \%$ of the eliminated surveys were among the recertification group.

\section{Characteristics of loggers}

Slightly over $60 \%$ were owners or operators of their own logging companies. Trainees worked in companies ranging in size from two to 23, with an average workforce of four to five employees. Owners and other workers performed a variety of jobs common to loggers including timber cutting, operating heavy equipment, and driving trucks. Respondents reported that slightly less than $40 \%$ of their companies had written safety programs with "task specific" guidelines. About one fifth of the loggers reported that their companies had participated in the West Virginia Loggers Safety Initiative Program. Other characteristics of loggers' companies are presented in table 1.

\section{Attitudes and knowledge of loggers}

On the day of training but before the formal video presentation, loggers were asked their opinions on a variety of safety issues. Although $80 \%(950 / 1180)$ agreed that logging is more dangerous than other "hands-on" jobs, half (596/1184) said accidents were part of the job. Just over half (568/1011) reported that they had experienced "close calls" in the course of their work. While logging operations may typically be governed by the number of trees felled and delivered to the mill, over three quarters (898/1184) of the loggers disagreed that they must take risks in order to make a profit. An overwhelming majority of the loggers felt that safety management (997/1172) and periodic meetings (983/ 1179) were important.

Immediately after viewing the video, 86\% (993/1153) reported that the information contained in the video was useful and 57\% (647/1143) indicated that the video was more

Table 1 Characteristics of logging companies, as reported by trainees, April 2002 to October 2003*

\begin{tabular}{ll}
\hline Characteristic & No (\%) \\
\hline $\begin{array}{l}\text { Trainees who were owner/operators of a logging } \\
\text { company }\end{array}$ & 731 (61.1) \\
$\begin{array}{l}\text { Trainees who reported that their company owners } \\
\text { were in charge of safety training }\end{array}$ & 978 (82.9) \\
$\begin{array}{l}\text { Trainees who reported that their companies had } \\
\text { written safety program with "task specific" guidelines }\end{array}$ & $443(38.0)$ \\
$\begin{array}{l}\text { Trainees who reported that safety training was also } \\
\text { provided to experienced loggers who were new } \\
\text { employees }\end{array}$ & 675 (63.1) \\
$\begin{array}{l}\text { Trainees who reported that their companies were } \\
\text { involved in the West Virginia Loggers Safety lnitiative }\end{array}$ & $256(22.0)$ \\
$\begin{array}{l}\text { Program } \\
\text { Trainees who reported that a copy of the OSHA logging }\end{array}$ & 546 (46.7) \\
standard was available at worksite & \\
\hline *Loggers did not answer all questions.
\end{tabular}


useful in comparison to the rest of the logger training components. Loggers were also asked 13 questions, repeated from the pre-training survey, to determine if there had been an improvement in knowledge as a result of viewing the video (see table 2 ). Several statistically significant improvements were noted, particularly with questions that were presented either by a diagram or picture (that is, the first four questions listed in table 2). For example, 54\% fewer loggers responded incorrectly in identifying the safest escape path after viewing the video indicating a $46 \%$ improvement. Other significant improvements were noted in the true/false questions, as well. After viewing the video, $8 \%$ fewer trainees incorrectly identified the distance from the stump where fatal incidents occur, resulting in a $92 \%$ improvement. While there were other statistically significant improvements noted in the last seven questions in table 2, very few loggers answered incorrectly before seeing the video. The question dealing with escape path and hinge wood showed a very minor yet unexpected increase in incorrect answers after viewing the video.

\section{Subgroup comparisons}

Table 3 summarizes subgroup comparisons on changes in safety knowledge for selected questions between loggers receiving certification $v$ recertification training, owners $v$ nonowners, and loggers in Loggers Safety Initiative $v$ nonLoggers Safety Initiative companies. Being an owner, a member of a company that participated in the Loggers Safety Initiative, or a certified logger at the time of training does not appear to overly influence observed changes in knowledge after viewing the video. There were some differences, however. For example, non-owners showed $13 \%$ more improvement in identifying the safest escape path than owners $(53 \% \vee 40 \%)$. Loggers from companies that didn't participate in the Loggers Safety Initiative showed 12\% greater improvement in identifying the safest notch compared with loggers from companies that did participate $(35 \%$ v 23\%).

\section{Behavior changes}

Approximately six months after their classroom sessions, loggers were called and asked questions relating to the safety training and their subsequent use of the video and field guide. Note: loggers did not answer all questions. Twenty one percent (246/1197) who received training were successfully contacted; overall, $17 \%$ of the baseline certification group (67/ 393 ) and $24 \%$ of the baseline recertification group (179/762). The video was shared with an additional 238 coworkers and copies of the field guide were given to 226 . Over half reported changed management and/or work site practices attributed to the video (132/240) and field guide (133/226). Anecdotally, many loggers said that the video increased their safety awareness and visually described safer work practices. Over ninety percent $(212 / 232)$ reported that they could relate to the true stories told in the video. In response to an open ended question on the utility of the field guide, many loggers indicated that it was an excellent and quick reference, taught them valuable tips on safe cutting and felling techniques, was used in "tail gate" safety meetings.

\section{DISCUSSION}

Loggers clearly indicated that their profession is hazardous and that safety is paramount in field operations. As self reported by loggers, the use of the video during training and the video and field guide later at the worksite resulted in many changed work habits and practices, as self reported by loggers. While statistically significant improvements were observed for 10 of the 13 questions covered in the video, we believe the four questions presented pictorially were the most relevant because they represented the most serious hazards identified through WVFACE field investigations. It is quite apparent that the video strongly influenced the loggers and improved their knowledge about the primary hazards in logging and ways to mitigate these hazards. We did, however, expect loggers receiving recertification training and those from companies participating in the Loggers Safety Initiative to answer fewer questions incorrectly before the video and show more improvement afterwards.

\begin{tabular}{|c|c|c|c|c|}
\hline Question/statement & $\begin{array}{l}\text { No }(\%) \text { responding } \\
\text { incorrectly at } \\
\text { pre-training (A) }\end{array}$ & $\begin{array}{l}\text { No (\%) responding } \\
\text { incorrectly at } \\
\text { post-training (B) }\end{array}$ & Ratio (B:A) & $\chi^{2}$ \\
\hline Identification of the safest escape path $\dagger$ & $402(33.6)$ & $218(18.2)$ & 0.54 & $77.7^{* * *}$ \\
\hline Identification of the safest notcht & $372(31.1)$ & $250(20.9)$ & 0.67 & $32.3^{* * *}$ \\
\hline Identification of overloaded log trucks $†$ & $353(29.5$ & $183(15.3)$ & 0.52 & $69.5^{\star * *}$ \\
\hline $\begin{array}{l}\text { Identification of the stump with the proper } \\
\text { amount of hinge woodt }\end{array}$ & $324(27.1)$ & $283(23.6)$ & 0.87 & $3.9^{*}$ \\
\hline $\begin{array}{l}\text { Safety meetings should be held once a } \\
\text { week }(\mathrm{T} / \mathrm{F}) \ddagger\end{array}$ & $213(17.8)$ & $38(3.2)$ & 0.18 & $136.3^{* * *}$ \\
\hline $\begin{array}{l}\text { Most fatal logging incidents occur within } \\
10 \text { feet of the stump of a felled tree (T/F) }\end{array}$ & $212(17.7)$ & $17(1.4)$ & 0.08 & $183.6^{* * *}$ \\
\hline $\begin{array}{l}\text { Most of the time, clearing and using an } \\
\text { escape path and leaving hinge wood are } \\
\text { unnecessary (T/F) }\end{array}$ & $176(14.7)$ & $193(16.1)$ & 1.10 & 0.9 \\
\hline $\begin{array}{l}\text { Owners/operators are responsible for } \\
\text { providing workers with safety equipment } \\
\text { and making sure they use it (T/F) }\end{array}$ & $23(1.9)$ & $11(0.9)$ & 0.47 & $4.3^{*}$ \\
\hline $\begin{array}{l}\text { To safely fell a tree, a clear fall path and } \\
\text { landing zone should be established (T/F) }\end{array}$ & $32(2.7)$ & $15(1.2)$ & 0.44 & $6.3^{*}$ \\
\hline $\begin{array}{l}\text { Owners/operators should conduct frequent } \\
\text { and regular job-site safety inspections (T/F) }\end{array}$ & $20(1.7)$ & $4(0.3)$ & 0.18 & $10.8^{* *}$ \\
\hline $\begin{array}{l}\text { To safely fell a tree, an escape path should } \\
\text { be used (T/F) }\end{array}$ & $16(1.3)$ & $7(0.6)$ & 0.46 & 3.6 \\
\hline $\begin{array}{l}\text { Safety should be the most important } \\
\text { consideration on a logging job (T/F) }\end{array}$ & $20(1.7)$ & $7(0.6)$ & 0.35 & $6.3^{*}$ \\
\hline Safety is everyone's responsibility (T/F) & $9(0.7)$ & $5(0.4)$ & 0.57 & 1.1 \\
\hline
\end{tabular}




\begin{tabular}{|c|c|c|c|c|}
\hline Question/statement & $\begin{array}{l}\text { No (\%) responding } \\
\text { incorrectly at } \\
\text { pre-training (A) }\end{array}$ & $\begin{array}{l}\text { No (\%) responding } \\
\text { incorrectly at } \\
\text { post-training (B) }\end{array}$ & Ratio (B:A) & $\chi^{2}$ \\
\hline \multicolumn{5}{|c|}{ Identification of the safest escape path } \\
\hline Certification (393) & $146(37.1)$ & $71(18.1)$ & 0.49 & $35.8^{* * *}$ \\
\hline Recertification (762) & $239(31.4)$ & $129(16.9)$ & 0.54 & $43.3^{\star \star \star}$ \\
\hline Owner (731) & $237(32.4)$ & $141(19.3)$ & 0.60 & $32.9^{\star \star *}$ \\
\hline Non-owner (456) & $164(36.0)$ & 77 (16.9) & 0.47 & $42.7^{\star \star \star}$ \\
\hline LSI (256) & $89(34.8)$ & $41(16.0)$ & 0.46 & $23.7^{* * *}$ \\
\hline Non-LSI (909) & $295(32.4)$ & $168(18.5)$ & 0.57 & $46.7^{* * *}$ \\
\hline \multicolumn{5}{|c|}{ Identification of the safest notch } \\
\hline Certification & $152(38.7)$ & $104(26.5)$ & 0.68 & $13.3^{* * *}$ \\
\hline Recertification & $205(26.9)$ & $135(17.7)$ & 0.66 & $18.6^{* * *}$ \\
\hline Owner & $219(30.0)$ & $153(20.9)$ & 0.70 & $15.1^{* * *}$ \\
\hline Non-owner & $150(32.9)$ & $96(21.0)$ & 0.64 & $16.3^{* * *}$ \\
\hline LSI & $62(24.2)$ & $48(18.7)$ & 0.77 & 2.3 \\
\hline Non-LSI & $299(32.9)$ & $197(21.7)$ & 0.65 & $28.8^{* * *}$ \\
\hline \multicolumn{5}{|c|}{ Identification of overloaded log trucks } \\
\hline Certification & $133(33.8)$ & $70(17.8)$ & 0.53 & $26.4^{* * *}$ \\
\hline Recertification & $207(27.2)$ & $105(13.8)$ & 0.51 & $41.9^{* * *}$ \\
\hline Owner & $215(29.4)$ & $114(15.6)$ & 0.53 & $40.0^{* * *}$ \\
\hline Non-owner & $136(29.8)$ & $67(14.7)$ & 0.49 & $30.2^{* * \star}$ \\
\hline LSI & $84(32.8)$ & $41(16.0)$ & 0.49 & $19.6^{\star \star \star}$ \\
\hline Non-LSI & $260(28.6)$ & $137(15.1)$ & 0.53 & $48.3^{\star \star \star}$ \\
\hline \multicolumn{5}{|c|}{ Safety meetings should be held once a week } \\
\hline Certification & 72 (18.3) & $7(1.8)$ & 0.10 & $59.5^{\star \star \star}$ \\
\hline Recertification & 130 (17.1) & $28(3.7)$ & 0.21 & $73.5^{\star \star \star}$ \\
\hline Owner & 131 (17.9) & $26(3.6)$ & 0.20 & $78.7^{* \star \star}$ \\
\hline Non-owner & 81 (17.8) & $12(2.6)$ & 0.15 & $57.0^{* \star *}$ \\
\hline LSI & $42(16.4)$ & $6(2.3)$ & 0.14 & $29.8^{\star \star \star}$ \\
\hline Non-LSI & 166 (18.2) & $31(3.4)$ & 0.19 & $102.7^{\star \star \star}$ \\
\hline \multicolumn{5}{|c|}{$\begin{array}{l}\text { Most fatal logging incidents occur within } 10 \\
\text { feet of the stump of a felled tree }\end{array}$} \\
\hline Certification & 70 (17.8) & $5(1.3)$ & 0.07 & $62.3^{* * *}$ \\
\hline Recertification & 133 (17.4) & 11 (1.4) & 0.08 & $114.1^{* \star *}$ \\
\hline Owner & 123 (16.8) & $8(1.1)$ & 0.06 & $110.9^{\star \star \star}$ \\
\hline Non-owner & 88 (19.3) & $9(2.0)$ & 0.10 & $72.0^{* * *}$ \\
\hline LSI & 34 (13.3) & $4(1.6)$ & 0.12 & $25.6^{* \star \star}$ \\
\hline Non-LSI & $171(18.8)$ & $12(1.3)$ & 0.07 & $153.6^{* * *}$ \\
\hline
\end{tabular}

A study by Egan et al is the only study that we are aware of that has reviewed West Virginia logger certification and training. ${ }^{32}$ In this study, $27 \%$ of the 1108 certified loggers responded to a mail survey with telephone follow up. The increased costs associated with training to meet OSHA and West Virginia regulatory requirements were a major concern to loggers. Despite the costs, loggers seemed to be pleased with the state mandated training and certification process. This study did not specifically address logger's knowledge and attitudes nor behavior changes resulting from training.

In our study, $22 \%$ of loggers responded that their companies were participating in the Loggers Safety Initiative, but it was not known for how long. In general, our Loggers Safety Initiative specific analyses suggest that being a logger for a participating company did not influence new knowledge to any significant degree. We were somewhat surprised that there was a $12 \%$ improvement differential in the identification of the safest notch between those working for companies not participating in the Loggers Safety Initiative (35\%) compared with those working for companies that did participate $(23 \%)$. While our study methodology was not designed to determine the impact of the Loggers Safety Initiative, ongoing research at the National Institute for Occupational Safety and Health is studying it in detail. ${ }^{33}$

A post-training survey of Kentucky loggers undergoing a three day training session reported that loggers felt training including first aid, cardiopulmonary resuscitation, forest ecology, and best management practices was worthwhile. ${ }^{34}$ The request for less emphasis on business issues and more emphasis on safety issues for future training was not surprising since less than $10 \%$ of the class were company owners. Similarly, while WVDOF logger training has been historically oriented towards best management practices, sustainable forest initiatives, and first aid, our added safety initiative has been fully adopted and has become a standard part of each training session. Ninety percent of the loggers contacted six months after their training indicated that the techniques and recommendations offered in the video and field guide were useful to them and had influenced change in their work habits. This finding does not agree with Bordas et al, whose observational research on five Alabama logging crews indicated loggers felt most safety recommendations are difficult to implement and negatively impact productivity. ${ }^{35}$

\section{Study limitations}

When we first completed the video we did not adequately control its initial release. Thus, a number of loggers viewed the video before their scheduled training. We realized this after the first month of sessions (March 2002) and quickly added a question to the pre-training survey asking if the logger had already seen the video. All surveys from March and April 2002 on which loggers indicated having seen the video were not included in our analyses.

During several of the early training sessions, we were lax in ensuring that consent forms were initialed and signed by the loggers and observed, after the fact, that some loggers did not identify themselves adequately on the surveys. As a result, incomplete consent forms and surveys were not included in 


\section{Key points}

- In West Virginia, logging is a hazardous industry leading to serious and often fatal injuries.

- Our training initiative yielded significant changes in the safety knowledge of West Virginia loggers. Future research should examine if such changes relate to observed work practices in the field or reductions in injury rates.

- Administering a survey during required training yielded a good response rate of usable surveys, as opposed to typically low response rates obtained from mail and phone contacts, and may be useful for future studies of loggers.

- Alternative funding of these programs should be identified so this new safety module can continue as a part of logger training.

the final database. In subsequent sessions, we were much more cognizant of these issues and when classes were large, additional WVDOF and research staff assisted. In hindsight, information about a logger's education and experience would have been very valuable in helping to better understand and explain observed differences among the subgroups.

For research purposes, this project is scheduled to continue through March 2005 in order to potentially train all certified loggers who must be recertified within three years of their initial training. WVDOF has indicated that, while this safety module has yielded positive results and has become well integrated into its logger training, continuance after the end of the project might be problematic in terms of manpower resources and time requirements.

The follow up rate was of concern. Initially, research staff made up to six calls, varying the time of day and day of week. Review of our success rate in the first six months indicated that three calls (no matter when attempted) would likely provide maximum contact and three additional calls added very few successful contacts. At that point, we decided not to attempt any more than three calls. A low response rate seems to be typical of the West Virginia certified logger population; other mail surveys of this group yielded similar response rates of $27 \%{ }^{32}$ and $30 \%{ }^{13}$ In contrast, administering a survey during a required training course yielded a very good response rate of usable surveys and may be useful for future logger studies. The ratio of recertified to certified loggers at training $(67 \% \vee 33 \%)$ changed slightly at follow up (73\% to $27 \%$ ) and the owner to non-owner ratio also changed slightly from $62 \%$ and $38 \%$, respectively to $57 \%$ and $43 \%$ at follow up. Neither change was unexpected.

Although our results have shown a change in safety knowledge and self reported work practices, it is unknown if these work habits were in fact carried out in the field, to what extent, and if they affect injuries and fatalities. We also do not know the impact the video and field guide may have on coworkers who may not have participated in the WVDOF training. While this safety initiative is scheduled to continue until all certified loggers are trained, the survey results reported herein were from a subset of the West Virginia logging community and results may not necessarily apply to the entire logging industry in West Virginia.

\section{ACKNOWLEDGEMENTS}

Research supported by Cooperative Agreement U60/CCU312914-06 from CDC/NIOSH for the West Virginia University Fatality Assessment and Control Evaluation Program. We appreciate the comments from Suzanne Marsh.
Authors' affiliations

J C Helmkamp, W J Lundstrom, J Ramprasad, A Haque, Center for Rural Emergency Medicine, West Virginia University, Morgantown, West Virginia, USA

J L Bell, Division of Safety Research, National Institute for Occupational Safety and Health, CDC, Morgantown, West Virginia, USA

\section{REFERENCES}

1 Sygnatur E. Logging is perilous work. Compensation and Working Conditions 1998;3(4):3-9 (winter).

2 Tippens RL, Langley RL. Epidemiology of forestry injuries and illnesses (chapter 29). In: Langley RL, Mclymore RL, Meggs WJ, et al, eds. Safety and health in agriculture, forestry, and fisheries. Rockville, MD: Government Institutes, 1997.

3 Vance EL. A review of logging fatalities investigated by the Occupational Safety and Health Administration in FY 1996 and FY 1997. Part 1 of 2. OSHA logging report, October 2000.

4 Leigh JP. Causes of death in the workplace. Westport, CN: Quorum Books, 1995.

5 Braddee RW. Preventing injuries and deaths of loggers. NIOSH Alert. Department of Health and Human Services, DHHS (NIOSH) publication No 95-101, December 1994.

6 Bureau of Labor Statistics. Work injury report-injuries in the logging industry. Bulletin 2203. Washington, DC: US Department of Labor, 1984

7 Bureau of Labor Statistics. Census of fatal occupational injuries, 2002. US Department of Labor Release 03-488, September 17 2003. Washington, DC: US Department of Labor.

8 Bureau of Labor Statistics. Census of Fatal Occupational Injuries. Available at: http://www.bls.gov/iif/oshwc/cfoi/cfch0001.pdf (accessed 12 November 2003).

9 Marsh SM, Layne LA. Fatal injuries to civilian workers in the United States, 1980-1995. National Institute for Occupational Safety and Health, Division of Safety Research. DHHS (NIOSH) Publication No 2001-129S, July 2001.

10 Myers JR, Fosbroke DE. Logging fatalities in the United States by region, cause of death, and other factors B 1980 through 1988. Journal of Safety Research 1994; 25:97-105.

11 Hassler CC, Wright RW, Sims HC. Analysis of West Virginia workers' compensation records for the wood products industry (1989-1990). Agricultural and Forestry Experiment Station, West Virginia University College of Agriculture and Forestry. Miscellaneous publication 24, September 1993.

12 Helmkamp JC, Kennedy RD, Fosbroke DE, et al. Occupational fatalities in the fishing, logging and air transport industries in Alaska, 1991. Scand J Work Environ Health 1992;18(suppl 2):55-7.

13 Helmkamp JC, Derk SJ. Nonfatal logging-related injuries in West Virginia. $J$ Occup Environ Med 1999;41:967-72.

14 Helmkamp JC, Lundstrom WJ. Work-related deaths in West Virginia from July 1996 through June 1999: surveillance, investigation, and prevention. J Occup Environ Med 2000;42:156-62

15 Bell JL, Helmkamp JC. Non-fatal injuries in the West Virginia logging industry: using workers' compensation claims to assess risk from 1995-2001. Am J Ind Med 2003:44:502-9.

16 Bell JL. Changes in logging injury rates associated with use of feller-bunchers in West Virginia. Journal of Safety Research 2002;33:463-471.

17 Williams JM, Borgman MA, Prescott JE. Injuries related to logging: epidemiology, etiology and implications for prevention. WV Med J 1996;92:320-323 (Nov/Dec).

18 Wolf CH, Dempsey GP. Logging work injuries in Appalachia. Southern Lumberman 1979;239:75-82.

19 Paulozzi L. Fatal logging injuries in Washington state, 1977 to 1983. J Occup Med 1987;29:103-8.

20 Pine JC, Marx BD, De Hoop CF. Characteristics of workers' compensation injuries for logging operations in Louisiana: 1985-1990. South Journal of Applied Forestry 1994; 18:110-15.

21 Rodriguez-Acosta RL, Loomis DP. Fatal occupational injuries in the forestry and logging industry in North Carolina, 1977-1991. Int J Occup Environ Health 1997;3:259-65.

22 Personick ME. Serious injury befall workers struck by objects. Fatal workplace injuries in 1996: a collection of data and analysis. USDL report 922. Washington, DC: Bureau of Labor Statistics, June 1998:20-4.

23 West Virginia Department of Health and Human Resources. Occupational safety and health. Healthy people 2010. Charleston, WV: Bureau for Public Health, May 2001 (chapter 20).

24 Bureau of Labor Statistics. Occupational injuries and illnesses in the United States: profiles data 1992-1999. CD-ROM version 7.6, national data. Washington, DC: US Department of Labor.

25 West Virginia Division of Environmental Protection. Logging Sediment Control Act, chapter 22, Code of West Virginia, 1992.

26 Forest Resources Association, Inc. Eighth report on the status of statewide logger training and education programs in thirty-two forested states. (02-A-2.) Rockville, MD: Forest Resources Association, Inc, April 2002

27 Occupational Safety and Health Administration. Logging standard 29CFR 1910.266. Washington, DC: US Department of Labor, 12 October 1994.

28 Carruth S. West Virginia Loggers Safety Initiative; loggers, mills, and government cooperate on loss control. Forest Operations Review 2000;2(2):8-14 (spring/summer). 
29 West Virginia Forestry Association. Loggers Safety Initiative. Available at: http://www.wvfa.org/loggers.htm (accessed 26 September 2001).

30 Agresti A. Categorical data analysis. New York: John Wiley and Sons, 1990

31 Conover WJ. Practical nonparametric statistics. 2nd Ed. New York: John Wiley, 1980.

32 Egan AF, Hassler CC, Grushecky ST. Logger certification and training: a view from West Virginia's logging community. Forest Products Journal 1997;47(7/8):46-50.
33 Bell JL. Evaluating the effectiveness of a logger training program in reducing injuries to loggers. Pittsburgh PA: NIOSH National Occupational Injury Research Symposium, 29 October 2003.

34 Reeb JE. Loggers' views on training after attending a three-day educational program. Journal of Natural Resources and Life Science Education 1996;25(1):43-6.

35 Bordas RM, Davis GA, Hopkins BL, et al. Documentation of hazards and safety perceptions for mechanized logging operations in east central Alabama. Journal of Agricultural Safety and Health 2001;7:113-23.

\section{COCHRANE CORNER}

\section{Cochrane Injuries Group}

he evidence based approach to healthcare is steadily making headway but there is much to do to build the evidence base on injury. Making an important contribution is the

Cochrane Injuries Group (CIG) (www.cochrane-injuries.lshtm.ac.uk), one of the 49 systematic review groups of the Cochrane Collaboration. CIG's remit includes the prevention and treatment of injury. Of the 45 reviews CIG has published to date, 12 deal with interventions for injury prevention and more are on the way. This regular column in Injury Prevention will look at new developments at the CIG editorial base, at the London School of Hygiene and Tropical Medicine. The School is a World Health Organization Collaborating Centre for Research and Training in Injury and Violence Prevention.

\section{Road traffic injuries}

Road traffic injuries are the leading cause of death by injury, taking 1.2 million lives around the world each year. With this year's World Health Day having focused on road safety, we are at CIG taking stock of what we have done in this area so far and trying to identify our future priorities.

Eight of our published systematic reviews deal with road safety:

- Area-wide traffic calming for preventing traffic related injuries.

- Graduated driver licensing for reducing motor vehicle crashes among young drivers.

- Helmets for preventing head and facial injuries in bicyclists.

- Interventions for increasing pedestrian and cyclist visibility for the prevention of death and injuries.

- Motorcycle helmets for preventing injury in motorcyclists.

- Post-licence driver education programmes for the prevention of traffic crashes.

- Safety education of pedestrians for injury prevention.

- School based driver education for the prevention of traffic crashes.

We have more in the pipeline, having published protocols for reviews of a further six interventions:

- Alcohol-ignition interlock programmes for reducing drink driving recidivism.

- Increasing motorcycle and rider conspicuity for preventing death and injury in motorcyclists.

- Interventions for promoting use of booster seats for children aged 4-6 travelling in cars.

- Non-legislative interventions for the promotion of cycle helmet wearing in children.

- Street lighting for the prevention of road traffic crashes.

- Speed enforcement detection devices for preventing road traffic injuries.

The last of these (speed cameras) has been hotly debated in the UK media over the last few months. Most of the popular press takes the line that speed cameras are not effective, except in creating extra income for the government. The debate has highlighted the need for a proper review of the evidence. Everyone has their own views as to whether speed cameras work or not, but, as yet, we cannot be sure who is right. Lively debate can of course serve to highlight important issues but if such debate is not informed by evidence then it will generate more heat than light.

There are many other interventions now in widespread use intended to cut death and injury on the road which have yet to be the subject of a systematic review. It would be helpful to know what readers of Injury Prevention think should be the priorities for new reviews. We would welcome any suggestions. Better still, we would be pleased to hear from anyone who would like to volunteer to write a review for us.

P I Chinnock Cochrane Injuries Group; paul.chinnock@|shtm.ac.uk 